\title{
INTELLIGENCE QUOTIENT (IQ) AND SEX: PREDICTORS OF ACADEMIC PERFORMANCE, EMOTIONAL STATE, SOCIAL ADAPTABILITY AND WORK ATTITUDE
}

\author{
${ }^{1}$ Andie Tangonan Capinding \\ ${ }^{1}$ Faculty Member of Nueva Ecija University of \\ Science and Technology-Gabaldon Campus, \\ Mathematics Department, \\ College of Education.
}

\author{
Czarina Ballesteros Ducut \\ Faculty member, \\ Ligaya National High School, \\ Gabaldon Nueva Ecija, \\ Philippines
}

Article DOI: https://doi.org/10.36713/epra6485

\begin{abstract}
This study focused on determining the association of $I Q$ and sex to academic performance, emotional state, social adaptability, and work attitude of the students taking education in NEUST-Gabaldon Campus. Questionnaires are administered to find out the association of IQ and sex to academic performance, emotional state, social adaptability, and work attitude. A descriptive - correlational design was employed in this study. The study showed that there is a significant association of sex to academic performance, emotional state, social adaptability and work attitude. It implied that sex can be use as a predictor of academic performance, emotional state, social adaptability and work attitude. Data also implied that in this population the male group are more academically equipped than the female counterpart. Data also showed that the female group are more emotional than the male counterpart. Furthermore, the male group are more socially active and work directed. There is a correlation of IQ to academic performance, emotional state, social adaptability and work attitude. It implies that IQ is a predictor of academic performance, emotional state, social adaptability and work attitude, but there is no significant association between sex and IQ.
\end{abstract}

KEYWORDS: Intelligence Quotient (IQ), sex, Academic Performance, Emotional State, Social Adaptability, Work Attitude.

\section{INTRODUCTION}

Throughout history, education is one of the most important aspects of life. We cannot afford to deal with the drastic change in society if we are not educated properly. Indeed, education is our way of life. Hence, it is substantial for every educator to determine the factors that determine student academic performance. It gives directions on how teachers provide learning activities to achieve a specific goal.

On the other hand, some researches provide data about the determinants of academic performance. Some of these researches focus on students' profile, motivation, attitude, sex, cognitive engagement, behavioural engagement, and other student-related factors. These students' related factors may have or may not have direct influenced students' academic performance. Hence, these factors may or may not provide an idea on the part of teachers on how to develop and impose a specific learning task. Also, these student-related factors are subjective since it does not provide a direct numerical relationship on students' academic performance.

Every learner is unique in their way, so educators provide varied activities to cater to those differences. Nonetheless, some students can learn either way. They can learn, even in their way, and that's have 
something to do with their intelligence. Intelligence is a very important key factor to determine the student's academic performance in school. Intelligence is a cognitive potentiality that helps to increase the learning abilities of the students. Every Curriculum aim is to test the intelligence level in this way both intelligence and academic achievements interrelated object (Dandagal, and Yarriswami, 2017).

Intelligence is defined as general cognitive problem-solving skills. A mental ability involved in reasoning, perceiving relationships and analogies, calculating, learning quickly... etc. Some psychologists have divided intelligence into subcategories. For example, Howard Gardner maintained that it is comprised of seven components: musical, bodilykinesthetic, logical-mathematical, linguistic, spatial, and interpersonal. Other definitions are: "Intelligence is what you do when you don't know what to do." "Intelligence is a hypothetical idea which we have defined as being reflected by certain types of behaviour (Dandagal, and Yarriswami, 2017).

Furthermore, the Culture Fair Intelligence Test, which has been validated and standardized for use in Nigeria, describes intelligence as the general mental capacity to quickly learn, solve novel problems, educe relationships, quickly process information correctly, think rationally, behave deliberately, and most effectively adjust to one's environment (Kpolovie, 2015)

Literature indicates that verbal skills have a greater connection with academic achievement than nonverbal abilities, according to Kaya, Juntune, and Stough (2015). Nonverbal abilities are linked to the ability to learn, while verbal abilities are linked to the readiness to learn. Both verbal (readiness) and nonverbal (potential) abilities should be assessed if intelligence scores are used to predict future academic performance. Besides, to recognize gifted and talented students, evaluation of verbal abilities should complement the assessment of nonverbal abilities so that they will be able to survive in advanced academic programs.

Besides, Kpolovie (2016) has shown that there is a statistically significant relationship between IQ and Mathematics achievement (0.499 and 0.495) when the English language is partially out of the range; and between IQ and English Language achievement (0.411 and 0.346 ) when Mathematics is partially out of the range, respectively, at junior and senior secondary school levels. The findings also showed overwhelming proof of intelligence stability (0.702) over four years in super corroboration of the fluid and crystalized theory of intelligence. The coefficient of partial determination unveiled that IQ accounts for 24.90 per cent to 24.50 per cent of the variance in Mathematics achievement, and 16.89 per cent to 11.97 per cent of the variance in English Language achievement.

Singh (2010) investigated senior secondary students' mental health in terms of spiritual intelligence, altruism, school environment, and academic achievement and discovered that male students had significantly higher academic achievement than female students; students living in urban areas had significantly higher academic achievement than students living in rural areas; and students living in urban areas had significantly higher academic achievement than students living in rural areas; academic achievement of students studying in aided schools was significantly higher than that of students studying in government schools; academic achievement of students studying in unaided schools was significantly higher than that of students studying in government schools; academic achievement of students studying in aided schools was significantly higher than that of students studying in government schools; academic achievement of students studying in aided schools was significantly higher than that of students studying in unaided schools.

Gurubasappa (2009) studied intelligence and self-concept as correlates of secondary school students' academic achievement to determine the relationship between academic achievement and intelligence and self-concept using a sample of 400 students and discovered that there was a highly significant correlation between academic achievement and intelligence and self-concept; there was a significant inverse relationship between academic achievement and intelligence and self-concept.

Skourdi and Rahim (2010) looked at the relationship between emotional intelligence and linguistic intelligence in the acquisition of vocabulary in 66 EFL junior students from Shiraz Azad and Shiraz Universities. The results showed that emotional intelligence and linguistic intelligence, emotional intelligence and vocabulary awareness, and linguistic intelligence and vocabulary knowledge all have a positive relationship. Emotional intelligence has been discovered to be an indicator of linguistic intelligence and vice versa. Furthermore, several regressions found that linguistic intelligence outperformed emotional intelligence in predicting receptive vocabulary awareness.

M. Kiss, A. Kotsis, and A. István Kun (2014) conclude that sex, intellectual intelligence, introvert or extrovert orientation, thinking or feeling personality preference, and, in some sections of the study, emotional intelligence and perceiving or assessing personality preference of the student all have a major 
effect on academic performance. But then, Capinding, A. (2021), showed in his study that there is no association between sex and academic performance. Also, Z. Ghabanchi and R. Rastegar (2014) found that the correlation between IQ and reading comprehension is greater than the link between total emotional intelligence and reading comprehension. Reading comprehension scores were found to have a significant relationship with certain emotional intelligence subscales, such as interpersonal skills, intrapersonal abilities, and stress management. It meant that IQ matters more than emotional intelligence when it comes to reading comprehension.

M. Mohzan, N. Hassan, and N. Halil (2012) look into the effect of emotional intelligence on academic achievement among students at Universiti Teknologi Mara's Education Faculty (UiTM). The information for their analysis was collected using a questionnaire that elicited information on the students' Emotional Intelligence level as well as their academic performance. According to the findings of their research, the respondents have a high degree of Emotional Intelligence. Two domains of Emotional Intelligence (Self-Emotion Assessment and Perception of Emotion) were found to be strongly and positively correlated with respondents' academic achievement. The study's findings have significant implications for the importance of Emotional Intelligence and its ties to academic performance in students, especially among pre-service teachers.

S. Nath, S. Ghosh, and S. Das (2015), on the other hand, found that EQ and IQ are negatively correlated and that there is no important association between EQ and academic success. According to them, based on the current results, larger samples can be included in future studies. The study's drawback is the study's limited sample size.

According to S.O. AlZboon (2013), social adaptation is one of the most significant issues directly relevant to human conduct, which is a reaction of a person attempting to harmonize his motives and desires on the one side, and the requirements of the world and different circumstances on the other; therefore, he is concerned with positive acts that bring satisfaction.

An adaptive person, on the other hand, enters the phases where his attitudes and acts correlate with the social environment in which he lives, finding a positive balance in his social ties with the social milieu around him, positively influencing all of his different life aspects, according to Anani (2000). As a consequence, social adaptation refers to an individual's integration of his reality, emotions, and internal culture with his environmental socio-cultural values, which may emerge from ideological and intellectual differences between him and his society, and then he attempts to adjust to achieve some kind of equilibrium between him and his surrounding environment, in which he can fulfil his needs (Abdullah, 2001).

An individual's social adaptation leads to a balance in his relationships with his environment, friends, and education, which will, of course, improve his achievement motivation and allow him to fully utilize his energies and abilities. According to Mayahi (2010), the achievement motive is the most important and is directly influenced by proper social environment adaptation. The researcher wants to see if there is a correlation between and among the students' intelligence quotient (IQ), sex, academic performance, emotional status, social adaptability, and work attitude using these data.

Generally, the research study aimed to determine the impact of Intelligence Quotient (IQ), and sex on the Academic performance, Emotional Status, Social Adaptability, and Work Attitude of Second Year BEED and BSED Students of Nueva Ecija University of Science and Technology - Gabaldon Campus, during the first semester, the school year 2020-2021.

Specifically, this study aims to answer the following question: How may the respondents be described in terms of Sex, Academic Performance, Intelligence Quotient, Emotional Status, Social Adaptability and Work Attitude. Is there a significant association between sex and the following: Intelligence Quotient (IQ); Academic Performance; Emotional Status; Social Adaptability; and Work attitude? Is there a significant relationship between and among the student's intelligence quotient, academic performance, emotional status, social adaptability, and work attitude? Hypotheses

There is no significant relationship between sex and the following variables: Intelligence Quotient; Academic Performance; Emotional Status; Social Adaptability; and Work attitude.

There is no significant relationship between and among the student's intelligence quotient, academic performance, emotional status, social adaptability, and work attitude.

\section{METHODS \\ Research Design}

The study utilized a descriptive - correlational design. Descriptive correlational design is a research design where it describes the relationship between variables without making causation. Descriptive correlational studies describe the variables and the relationships that occur naturally between and among them (SousaI, V., et. al., 2007). 
ISSN (Online): 2455-3662

EPRA International Journal of Multidisciplinary Research (IJMR) - Peer Reviewed Journal Volume: 7 | Issue: 3 | March 2021|| Journal D0I: 10.36713/epra2013 || SJIF Impact Factor 2021:7.147 ||ISI Value: 1.188

Participants of the Study :The participants of the NEUST-Gabaldon Campus, A.Y. 2019-2020. study were the Second year BEED and BSE students of

Table 1 shows the distribution of the participants of the study.

Table 1 The Participants of the Study

\begin{tabular}{cccc}
\hline 2nd Year & MALE & FEMALE & TOTAL \\
\hline BSED & 4 & 19 & 23 \\
BEED & 4 & 19 & 23 \\
\hline Total & 8 & 38 & 46 \\
\hline
\end{tabular}

\section{Materials and Instrument}

The study provides a check-list and IQ test The Intelligence Quotient is done through IQTest.com. Questionnaire on Emotional status was adapted from the study of Aluoja, Shlik, Vasar, Luuk, and Leinsalu (Development and psychometric properties of the Emotional State Questionnaire, a self-report questionnaire for depression and anxiety). Questionnaire on Social Adaptability was adapted from the study of Saleem Odeh AlZboon (2013), Social Adaptation and Its Relationship to Achievement Motivation among High School Students in Jordan. Questionnaire on Work attitude was retrieved from Shodganga.inflib.net.ac.in. Student's grades were taken from last academic year (2019-2020).

\section{Reliability of Instruments}

The test-retest method was utilized in establishing the reliability of the questionnaire. It was administered twice to the 15 third year BEED students of the NEUST-Gabaldon campus who were not involved in the study. The scores of the respondents were correlated using Spearman's rho, with a reliability quotient of 0.89 .

\section{Data Collection}

Due to the restriction of face-to-face classes, data from the students were collected using google forms.

\section{DATA ANALYSIS Using SPSS}

Table 2 Statistical Tools

\begin{tabular}{|c|c|c|c|c|c|}
\hline & $\begin{array}{l}\text { Intelligence } \\
\text { Quotient }\end{array}$ & Sex & $\begin{array}{c}\text { Academic } \\
\text { performance }\end{array}$ & Social Adaptability & Work Attitude \\
\hline $\begin{array}{c}\text { Academic } \\
\text { performance }\end{array}$ & Pearson $r$ & $\begin{array}{l}\text { Point bi- } \\
\text { serial }\end{array}$ & & Pearson $r$ & Pearson $r$ \\
\hline $\begin{array}{c}\text { Emotional } \\
\text { Status }\end{array}$ & Ordinal by Interval & Chi-square & Pearson $r$ & Spearman's rho & Spearman's rho \\
\hline $\begin{array}{c}\text { Social } \\
\text { Adaptability }\end{array}$ & Ordinal by Interval & Chi-square & & & \\
\hline $\begin{array}{c}\text { Work } \\
\text { Attitude }\end{array}$ & Ordinal by Interval & Chi-square & & & Spearman's rho \\
\hline Sex & Point bi-serial & & & & \\
\hline
\end{tabular}

All hypotheses were tested at .05 level of significance.

The Scale and verbal interpretation of Academic Performance and Intelligent Quotient are given below: 
ISSN (Online): 2455-3662

EPRA International Journal of Multidisciplinary Research (IJMR) - Peer Reviewed Journal Volume: 7 | Issue: 3 | March 2021|| Journal DOI: 10.36713/epra2013 || SJIF Impact Factor 2021:7.147 ||ISI Value: 1.188

Table 3: Descriptors and Grading Scale

\begin{tabular}{|c|c|}
\hline Descriptor & Grading Scale \\
\hline Outstanding & $90-100$ \\
\hline Very Satisfactory & $85-89$ \\
\hline Satisfactory & $80-84$ \\
\hline Fairly Satisfactory & $75-79$ \\
\hline Did not meet the expectation & Below 75 \\
\hline
\end{tabular}

Table 4: IQ Classification and Range

\begin{tabular}{|l|c|}
\hline Classification & Ranges \\
\hline Very Gifted or Highly Advanced & $145-160$ \\
\hline Gifted or Very Advanced & $130-144$ \\
\hline Superior & $120-129$ \\
\hline High Average & $110-119$ \\
\hline Average & $90-109$ \\
\hline Low Average & $80-89$ \\
\hline Borderline & $70-79$ \\
\hline Mildly Impaired & $55-69$ \\
\hline Moderately Impaired & $40-54$ \\
\hline
\end{tabular}

The weighted mean and verbal interpretation were utilized in computing the responses of the

students on their Emotional Status, Social Adaptability, and Work Attitude. The arbitrary scale used:

Table 5

\begin{tabular}{|c|c|c|}
\hline Scale & $\begin{array}{c}\text { Emotional State and Social } \\
\text { Adaptability }\end{array}$ & Work Attitude \\
\hline $1.00-1.79$ & not at all & very low \\
\hline $1.80-2.59$ & seldom & low \\
\hline $2.60-3.39$ & sometimes & medium \\
\hline $3.40-4.19$ & often & high \\
\hline $4.20-5.00$ & all the time & very high \\
\hline
\end{tabular}

PRESENTATION, ANALYSIS AND INTERPRETATION OF DATA

Profile of the respondents in terms of Sex, Academic Performance, Intelligence Quotient, Emotional Status, Social Adaptability, and Work Attitude.

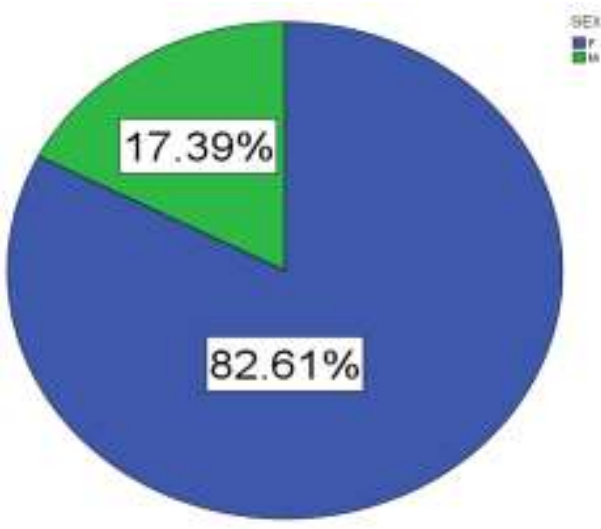

Figure 1. Distribution of the Respondents According to sex. 
Figure 1 showed that 82.61 per cent of the respondents are female, and 17.39 per cent are male.
It also implied that a great number of female students are taking education in NEUST-Gabaldon Campus.

Figure 2. Distribution of the Respondents According to Academic Performance.

\section{IQ Distribution}

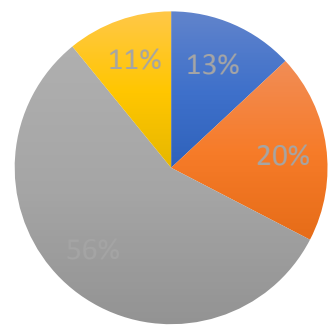

Figure 2 showed that most of the respondents have fairly satisfactory grades $(39 \%)$, followed by very satisfactory $(39 \%)$, outstanding $(15 \%)$, and the least satisfactory $(11 \%)$.
It implied that most of the students taking education have a fairly and very satisfactory grade. Furthermore, there is a need for uplifting the performance of the students taking education.

Figure 3. Distribution of Respondent According to "IQ"

\section{Academic Performance}

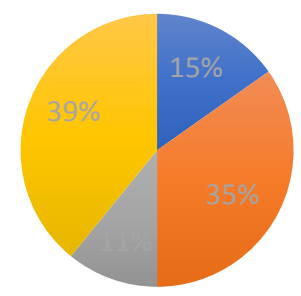

The chart showed that most of the respondent (56\%) have average IQ, followed by high average IQ $(20 \%)$, superior (13\%) and the least low average (11\%).
It also showed that most of the students taking education in Gabaldon Campus have an average IQ level. 
ISSN (Online): 2455-3662

EPRA International Journal of Multidisciplinary Research (IJMR) - Peer Reviewed Journal

Volume: 7 | Issue: 3 | March 2021 || Journal DOI: 10.36713/epra2013 || SJIF Impact Factor 2021:7.147 ||ISI Value: 1.188

Table 6. Weighted Mean and Verbal Description of Respondent's Emotional State.

\begin{tabular}{lcl} 
Emotional State & WM & Verbal Description \\
\hline Feelings of sadness & 3.141 & Sometimes \\
\hline Feeling no interest or pleasure in things & 2.845 & Sometimes \\
\hline Fear of being outside the home alone & 2.704 & Sometimes \\
\hline Feeling afraid of travelling by bus, train, or car & 2.732 & Sometimes \\
\hline Feeling easily irritated or annoyed & 3.127 & Sometimes \\
\hline Tension or inability to relax & 2.901 & Sometimes \\
\hline Fatigue or loss of energy & 3.127 & Sometimes \\
\hline Being easily fatigued & 2.901 & Sometimes \\
\hline Difficulty falling asleep & 3.282 & Sometimes \\
\hline Restless or disturbed sleep & 3.197 & Sometimes \\
\hline Total Weighted Mean & $\mathbf{2 . 9 9 6}$ & Sometimes
\end{tabular}

Table 6 showed that the respondent's emotional state are verbally interpreted as sometimes: "feelings of sadness" ( $w m=3.141)$; "feeling no interest or pleasure in things" (wm=2.845); "fear of being outside home alone" (wm=2.704); "feeling afraid of travelling by bus, train, or car" ( $w m=2.732)$; "feeling easily irritated or annoyed" (wm=3.127); "tension or inability to relax" ( $w m=2.901)$; "fatigue or loss of energy" ( $(w m=3.127)$; "being easily fatigued" (wm=2.901); "difficulty falling asleep" (wm=3.282); and "restless or disturbed sleep" (wm=3.197). The respondents sometimes felt those negative emotions with a total average of 2.996 .

It implied that the respondents sometimes felt negative emotions and it is natural for them to have these feelings. During this time of the pandemic, we cannot eliminate the fact that sometimes we felt negative emotions. Furthermore, it is necessary to conduct stress debriefing for the students and help them to cope with the new normal of the education system.

Table 7. Weighted Mean and Verbal Description of Respondent's Social Adaptability.

\begin{tabular}{lrl}
\hline Social Adaptability & Wm & Verbal Description \\
\hline I feel comfortable when I'm with my family & 4.38 & all the time \\
\hline I join my family in all social activities & 3.394 & Sometimes \\
\hline I enjoy it with my friends in their rituals & 3.38 & Sometimes \\
\hline $\begin{array}{l}\text { Being within a funny group of students takes me away from my } \\
\text { fears }\end{array}$ & 3.7 & Sometimes \\
\hline I accept constantly communicating with new friends & 3.732 & Sometimes \\
\hline Better to sit by myself at social events & 3.028 & Sometimes \\
\hline I am happy to create new social relationships & 3.676 & Often \\
\hline Participate in social events & 2.972 & Sometimes \\
\hline Be sure to participate in school activities & 3.197 & Sometimes \\
\hline I miss the familiarity with my colleagues in the school & 3.986 & Often \\
\hline Total Weighted Mean & $\mathbf{3 . 5 4 5}$ & Often \\
\hline
\end{tabular}

Table 7 shows the item-statements on Social Adaptability of the students, "they felt comfortable when they are in their family", $(w m=4.38)$ which can be interpreted as "all the time". They sometimes "join their family in all social activities" (wm=3.394), "enjoy their companies with their friends in their rituals" $(\mathrm{wm}=3.38)$, "being within a funny group of students takes them away from their fears" (wm=3.7), "they 
accept the constantly communicating with new friends" $(w m=3.732)$, "better to sit by their self in social events" $(w m=3.028)$, "they participate in social events" $(\mathrm{wm}=2.972)$, and "they are sure to participate in school activities" (wm=3.197). The respondents are often socially adaptive $(\mathrm{wm}=3.545)$.
The data showed that the respondents are often socially adaptive. They often participate and collaborate with social activities. It also showed that the students in this group can adapt to societal change that takes place drastically.

Table 8. Weighted Mean and Verbal Description of Respondent's Work Attitude.

\begin{tabular}{|c|c|c|}
\hline Work Attitude & WM & $\begin{array}{l}\text { Verbal } \\
\text { Description }\end{array}$ \\
\hline Opportunity for developing a sense of security in your life. & 3.267606 & medium \\
\hline Assuming greater personal responsibility. & 3.408451 & High \\
\hline Opportunity for independent thought and action. & 3.394366 & medium \\
\hline $\begin{array}{l}\text { Opportunity for growth and self-fulfilment by using your } \\
\text { unique abilities and realizing your potential. }\end{array}$ & 3.267606 & medium \\
\hline $\begin{array}{l}\text { The opportunity for the feeling of greater personal } \\
\text { achievement given by work. }\end{array}$ & 3.140845 & medium \\
\hline $\begin{array}{l}\text { The opportunity for growth and self-fulfilment by using } \\
\text { unique abilities and realizing potentials, given by work. }\end{array}$ & 3.197183 & medium \\
\hline $\begin{array}{l}\text { The opportunity for independent thought and action given } \\
\text { by work. }\end{array}$ & 3.309859 & medium \\
\hline $\begin{array}{l}\text { The opportunity for maintaining a comfortable standard } \\
\text { of living given by work. }\end{array}$ & 3.126761 & medium \\
\hline $\begin{array}{l}\text { The opportunity to assume greater personal responsibility } \\
\text { allowed by the family. }\end{array}$ & 3.507042 & High \\
\hline $\begin{array}{l}\text { The opportunity to assume greater personal responsibility } \\
\text { allowed by work. }\end{array}$ & 3.352113 & medium \\
\hline Total Weighted Mean & 3.297183 & medium \\
\hline
\end{tabular}

Table 8 shows the respondents work attitude, they have medium recognition on the item statements: "opportunity for developing a sense of security in your life" ( $w m=3.26)$; "opportunity for independent thought and action" (wm=3.39); "opportunity for growth and self-fulfilment by using your unique abilities and realizing your potential" ( $\mathrm{wm}=3.27)$; "the opportunity for the feeling of greater personal achievement given by work" (wm=3.14); "the opportunity for growth and self-fulfilment by using unique abilities and realizing potentials, given by work" $(w m=3.20)$; "the opportunity for independent thought and action given by work" ( $w m=3.31)$; "the opportunity for maintaining a comfortable standard of living given by work"
( $w m=3.13)$; and "the opportunity to assume greater personal responsibility allowed by work" ( $\mathrm{wm}=3.35)$. On the other hand, they have high recognition on the following item-statements: "assuming greater personal responsibility" ( $w m=3.41$ ); and "the opportunity to assume greater personal responsibility allowed by the family" (wm=3.51). The total weighted mean is 3.30 , which can be interpreted as "medium".

The data showed that the respondents have a medium recognition or though on their work attitude. It also shows that the students have a positive attitude towards accepting responsibilities. In addition, students showing a positive attitude towards work or job also showed a positive attitude towards learning.

Table 9. Weighted Mean of Male and Female Academic Performances. Group Statistics

\begin{tabular}{|l|c|c|c|c|c|}
\hline & SEX & $\mathbf{N}$ & Mean & Std. Deviation & $\begin{array}{c}\text { Std. Error } \\
\text { Mean }\end{array}$ \\
\hline \multirow{2}{*}{ ACAD.PERFORMANCE } & $\mathrm{F}$ & 3964 & 83.4929 & 6.22990 & .09895 \\
& $\mathrm{M}$ & 851 & 84.0047 & 4.13393 & .14171 \\
\hline
\end{tabular}


Table 9 showed the female and male have an average grade of 83.4929 and 84.0047 respectively.
It showed that the male group and female group shows a slight difference in their academic performance.

Table 10. Weighted Mean of Male and Female Intelligence Quotient.

Group Statistics

\begin{tabular}{|r|l|r|r|r|c|}
\hline & SEX & $\mathrm{N}$ & Mean & Std. Deviation & $\begin{array}{c}\text { Std. Error } \\
\text { Mean }\end{array}$ \\
\hline IQ & F & 3964 & 106.2619 & 14.28289 & .22686 \\
& M & 851 & 107.1152 & 8.90371 & .30522 \\
\hline
\end{tabular}

Table 10 showed the Female and Male have an average IQ of 106.2619 and 107.1152 respectively.
It shows that there is a slight difference between the IQ of male and female students.

Table 11. Correlation of Sex to the following: Academic Performance and Intelligence Quotient.

\begin{tabular}{|c|c|c|}
\hline & & SEX \\
\hline \multirow[t]{3}{*}{ SEX } & $\begin{array}{l}\text { Pearson Correlation } \\
\text { Sig. (2-tailed) }\end{array}$ & 1 \\
\hline & $\mathrm{N}$ & 4815 \\
\hline & Pearson Correlation & $.033^{*}$ \\
\hline \multirow[t]{3}{*}{ ACADPERFORMANCE } & Sig. (2-tailed) & .022 \\
\hline & $\mathrm{N}$ & 4815 \\
\hline & Pearson Correlation & .024 \\
\hline \multirow[t]{2}{*}{ IQ } & Sig. (2-tailed) & .094 \\
\hline & $\mathrm{N}$ & 4815 \\
\hline
\end{tabular}

*. Correlation is significant at the 0.05 level (2-tailed).

**. Correlation is significant at the 0.01 level (2-tailed).

Table 11 showed that there is a significant association between sex and academic performance with a p-value of $0.024(\mathrm{p}<0.5)$, but there is no significant association between sex and IQ with a p-value of $0.094(\mathrm{p}>0.05)$.
It implied that the male group excel over the female group in terms of academic performance. It also showed that male students are academically equipped than their female counterpart. 
ISSN (Online): 2455-3662

EPRA International Journal of Multidisciplinary Research (IJMR) - Peer Reviewed Journal

Volume: 7 | Issue: 3 | March 2021|| Journal DOI: 10.36713/epra2013 || SJIF Impact Factor 2021:7.147 ||ISI Value: 1.188

Table 12. Summary of Weighted Means of Students Emotional State, Social Adaptability, and Work Attitude.

\begin{tabular}{|ll|c|c|c|}
\hline \multicolumn{5}{c|}{ Report } \\
& & emotional & socialadap & WORKAttitude \\
\hline \multirow{4}{*}{$\mathrm{F}$} & Mean & 2.9768 & 3.6075 & 3.3233 \\
& $\mathrm{~N}$ & 3964 & 3964 & 3964 \\
& Std. Deviation & .67400 & .42877 & .53568 \\
& Skewness & -.401 & -.923 & .729 \\
& Mean & 2.8712 & 3.4839 & 3.1215 \\
& $\mathrm{~N}$ & 851 & 851 & 851 \\
$\mathrm{M}$ & Std. Deviation & .71218 & .52028 & .40841 \\
& Skewness & .244 & -.688 & -1.345 \\
& & & & \\
\hline
\end{tabular}

Table 12 shows the means of the Female and Male group on their Emotional State, Social Adaptability and Work Attitude. On their emotional state, the female and male group have an average rating of 2.97 and 2.87 respectively. On their Social Adaptability rating, the female and female group have 3.6 and 3.48 respectively. On their Work Attitude, the female and male group have an average rating of 3.32 and 3.12 respectively.

Table 13. Correlation of Sex to the following: Emotional State, Social Adaptability, and Work Attitude.

\begin{tabular}{|c|c|c|c|}
\hline \multicolumn{4}{|c|}{ Chi-Square Tests (Sex and Emotional State) } \\
\hline & Value & df & Asymp. Sig. (2-sided) \\
\hline $\begin{array}{l}\text { Pearson Chi-Square } \\
\text { Likelihood Ratio } \\
\text { Linear-by-Linear } \\
\text { Association } \\
\mathrm{N} \text { of Valid Cases }\end{array}$ & $\begin{array}{c}4161.412^{\mathrm{a}} \\
3893.184 \\
16.798 \\
4815\end{array}$ & $\begin{array}{c}26 \\
26 \\
1\end{array}$ & $\begin{array}{l}.000 \\
.000 \\
.000\end{array}$ \\
\hline \multicolumn{4}{|c|}{ Chi-Square Tests (Sex and Social Adaptability) } \\
\hline & Value & df & Asymp. Sig. (2-sided) \\
\hline $\begin{array}{l}\text { Pearson Chi-Square } \\
\text { Likelihood Ratio } \\
\text { Linear-by-Linear } \\
\text { Association } \\
\mathrm{N} \text { of Valid Cases }\end{array}$ & $\begin{array}{r}1094.503^{\mathrm{a}} \\
1220.232 \\
53.150 \\
4815\end{array}$ & $\begin{array}{r}14 \\
14 \\
1\end{array}$ & $\begin{array}{l}.000 \\
.000 \\
.000\end{array}$ \\
\hline \multicolumn{4}{|c|}{ Chi-Square Tests (Sex and Work Attitude) } \\
\hline & Value & df & Asymp. Sig. (2-sided) \\
\hline $\begin{array}{l}\text { Pearson Chi-Square } \\
\text { Likelihood Ratio } \\
\text { Linear-by-Linear } \\
\text { Association } \\
\mathrm{N} \text { of Valid Cases }\end{array}$ & $\begin{array}{r}2120.115^{\mathrm{a}} \\
2288.033 \\
105.076 \\
4815\end{array}$ & $\begin{array}{r}16 \\
16 \\
1\end{array}$ & $\begin{array}{l}.000 \\
.000 \\
.000\end{array}$ \\
\hline
\end{tabular}

a. 0 cells (0.0\%) have an expected count of less than 5 . The minimum expected count is 16.61 .
The mean of the female group on an emotional state is greater than the male group. However, in social adaptability and work attitude, the means of the male group is much greater than the female group. By this, we can say that most of the female students are emotional than the male counterpart. On the other hand, male students are more work directed and more socially adaptive than the female counterpart.
Chi-Square Tests (Sex and Emotional State)
Pearson Chi-Square

Linear-by-Linear

Association

$\mathrm{N}$ of Valid Cases 
Table 13 shows that there is a highly significant association between sex and emotional state 0.000 $(p<0.01)$, between sex and social adaptability 0.000 $(\mathrm{p}<0.01)$, and between sex and work attitude 0.000 $(\mathrm{p}<0.01)$.
The data shows that most of the female group felt negative emotions or become emotional than the male group. Likewise, most of the male group are more socially adaptive and have positive views about work.

Parkins, R. (2012), showed that women are still be more emotionally expressive gender.

Table 14. Correlation Between and Among Academic Performance, Intelligence Quotient, Emotional State, Social Adaptability, and Work Attitude.

\section{Correlations}

\begin{tabular}{|c|c|c|c|c|c|c|}
\hline & & $\begin{array}{c}\text { AcadPERFORM } \\
\text { ANCE }\end{array}$ & $\overline{I Q}$ & emotional & $\overline{\text { socialadap }}$ & $\begin{array}{c}\text { WORKAttit } \\
\text { ude }\end{array}$ \\
\hline \multirow{3}{*}{$\begin{array}{l}\text { AcadPERFORMAN } \\
\text { CE }\end{array}$} & $\begin{array}{l}\text { Pearson } \\
\text { Correlation }\end{array}$ & 1 & $.710^{* *}$ & $-.239^{* *}$ & $.116^{* *}$ & $.454^{* *}$ \\
\hline & Sig. (2-tailed) & & .000 & .000 & .000 & .000 \\
\hline & $\mathrm{N}$ & 4815 & 4815 & 4815 & 4815 & 4815 \\
\hline \multirow{3}{*}{ IQ } & $\begin{array}{l}\text { Pearson } \\
\text { Correlation }\end{array}$ & $.710^{* *}$ & 1 & $-.241^{* *}$ & $.257^{* *}$ & $.388^{* *}$ \\
\hline & Sig. (2-tailed) & .000 & & .000 & .000 & .000 \\
\hline & $\mathrm{N}$ & 4815 & 4815 & 4815 & 4815 & 4815 \\
\hline \multirow{3}{*}{ emotional } & $\begin{array}{l}\text { Pearson } \\
\text { Correlation }\end{array}$ & $-.239^{* *}$ & $-.241^{* *}$ & 1 & $-.133^{* *}$ & $-.392^{* *}$ \\
\hline & Sig. (2-tailed) & .000 & .000 & & .000 & .000 \\
\hline & $\mathrm{N}$ & 4815 & 4815 & 4815 & 4815 & 4815 \\
\hline \multirow{4}{*}{ socialadap } & $\begin{array}{l}\text { Pearson } \\
\text { Correlation }\end{array}$ & $.116^{* *}$ & $.257^{* *}$ & $-.133^{* *}$ & 1 & $.099^{* *}$ \\
\hline & Sig. (2-tailed) & .000 & .000 & .000 & & .000 \\
\hline & $\mathrm{N}$ & 4815 & 4815 & 4815 & 4815 & 4815 \\
\hline & $\begin{array}{l}\text { Pearson } \\
\text { Correlation }\end{array}$ & $.454^{* *}$ & $.388^{* *}$ & $-.392^{* *}$ & $.099^{* *}$ & 1 \\
\hline \multirow{2}{*}{ WORKAttitude } & Sig. (2-tailed) & .000 & .000 & .000 & .000 & \\
\hline & $\mathrm{N}$ & 4815 & 4815 & 4815 & 4815 & 4815 \\
\hline
\end{tabular}

**. Correlation is significant at the 0.01 level (2-tailed).

Table 14 shows that there is a highly significant relationship between Academic Performance and IQ $\left(\mathcal{K}^{2}=0.71, \mathrm{p} 0.000<0.01\right)$, between Academic Performance and Emotional State $\left(\boldsymbol{x}^{2}=\right.$ 0.239 , p0.000<0.01), between Academic Performance and Social Adaptability $\left(\boldsymbol{\varkappa}^{2}=0.116, \mathrm{p} 0.000<0.01\right)$, between Academic Performance and Work Attitude $\left(\boldsymbol{\chi}^{2}=0.454, \mathrm{p} 0.000<0.01\right)$, between IQ and Emotional State $\left(\mathcal{K}^{2}=-0.241, \mathrm{p} 0.000<0.01\right)$, between IQ and Social Adaptability $\left(\boldsymbol{\chi}^{2}=0.257, \mathrm{p} 0.000<0.01\right)$, between IQ and Work Attitude $\left(\boldsymbol{X}^{2}=0.388, \mathrm{p} 0.000<0.01\right)$, between Emotional State and Social Adaptability $\left(\mathcal{X}^{2}=-0.133\right.$, p0.000<0.01), between Emotional State and Work Attitude $\left(\boldsymbol{x}^{2}=-0.392, \mathrm{p} 0.000<0.01\right)$, and between Social Adaptability and Work Attitude $\left(\boldsymbol{x}^{2}=0.099\right.$, p0.000<0.01).

It implies that the students who have higher IQ, have better academic performance, the better their emotional state, the better they can mingle or adapt to the societal change, and the better they perform in their work.

Intelligence was correlated with higher academic performance among those with high skill, but not among those with low ability, according to Patrick C.L. Heaven and Joseph Ciarrochi (2012), and this impact was consistent across various subjects and parametric and nonparametric studies. When other personality features were controlled, the effect was not removed. We discuss the impact on understanding and improved academic performance of these findings.

Table 13 also shows that students who have negative emotions tend to have a decline in their work attitude and a decline in their interpersonal relationship with others since the correlation of emotional state towards work attitude and social adaptability is negative. It also implied that students who have better 
interpersonal relationship with others also tend to have positive thoughts about work.

\section{CONCLUSIONS}

The data collected implies that a great number of female students are taking education in Gabaldon Campus. Most of the students taking education in Gabaldon Campus have a fairly and very satisfactory grade. Most of the students taking education in Gabaldon Campus have an average IQ level. The respondents sometimes felt negative emotions and it is natural for them to have these feelings. During this time of the pandemic, we cannot eliminate the fact that sometimes we felt negative emotions. The respondents are often socially adaptive. They often participate and collaborate with social activities. It also showed that the students in this group can adapt to societal change that takes place drastically. The respondents have a medium recognition or though on their work attitude. It also shows that the students have a positive attitude towards accepting responsibilities. The male group have a higher academic grade than the female group. There is a slight difference in their IQ. Furthermore, there is an association between gender and academic performance. It implied that the male group excel over the female group in terms of academic performance. The means of the female group on an emotional state is greater than the male group. However, in social adaptability and work attitude, the means of the male group is much greater than the female group. Most of the female group felt negative emotions or become emotional than the male group. Likewise, most of the male group are more socially adaptive and have positive thought about work. Students who have higher IQ, have better academic performance, the better their emotional state, the better they can mingle or adapt to the societal change, and the better they perform in their work. It also shows that students who have negative emotions tend to have a decline in their work attitude and a decline in their interpersonal relationship with others since the correlation of emotional state towards work attitude and social adaptability is negative. It also implied that students who have better interpersonal relationship with others also tend to have positive thoughts about work.

\section{RECOMMENDATION}

The institution should also motivate the incoming male first-year students to take education as their course. Although IQ may consider as determinants of students' academic performance, it is substantial that School officials and faculty should constantly plan activities that will engage students in improving their skills and knowledge. There should be a strategic plan to improve student performance. The institution should give emotion debriefing to their students. Further research should conduct in this study.

\section{DEDICATION}

This humble work is dedicated to my wife, MRS. CHARLINE B. CAPINDING; to my mother, MRS. LORIE T. CAPINDING; to my daughter, CAILYN ANNE B. CAPINDING; and to my siblings, ROCHELLE and LAIANNE, for their unwavering support and affection. Most importantly, to our ALLPOWERFUL GOD.

\section{REFERENCES}

1. Aluoja A, Shlik J, Vasar V, Luuk K, Leinsalu M. (1999). Development and psychometric properties of the Emotional State Questionnaire, a self-report questionnaire for depression and anxiety. Nord $J$ Psychiatry 1999;53:443-449. Oslo. ISSN 08039488.

2. AlZboon, S. (2013). Social Adaptation and Its Relationship to Achievement Motivation among High School Students in Jordan. The World Islamic Sciences \& Education, Faculty of Arts And Educational Sciences, Jordan. Tel: 962-777-467861. E-mail: drzboon@yahoo.com. URL: http://dx.doi.org/10.5539/ies.v6n10p63

3. Capinding, Andie $T$. (2021). Academic Performance Among Minority Students in Dingalan National High School. International Journal of Engineering Science and Computing (IJESC.org), ISSN 2321-3361, Volume-11|Issue-02| Feb-2021. ISSN 2250-1371.

4. Dandagal, S.N., Yarriswami, IIDr.M.C. (2017). A Study of Intelligence in Relation to Academic Achievement of Secondary School Students. International Journal of Advanced Research in Education \& Technology (IJARET). ISSN : 23942975 (Online).

5. Ghabanchi, Z., Rastegar, $R$. (2014). The Correlation of $I Q$ and Emotional Intelligence with Reading Comprehension. The Reading Matrix (C) 2014 Volume 14, Number 2, September 2014

6. Kaya, Fatih \& Juntune, Joyce \& Stough, Laura. (2015). Intelligence and Its Relationship to Achievement. Ilkögretim Online. 14. 10.17051/io.2015.25436.

7. Kiss M., Kotsis A., Kun A.I. (2014). The Relationship Between Intelligence, Emotional Intelligence, Personality Styles and Academic Success. Business Education \& Accreditation. Volume 6 Number 22014

8. Kpolovie, P. J. (2015). INTELLIGENCE AND ACADEMIC ACHIEVEMENT: A LONGITUDINAL SURVEY. International Journal of Health and Psychology Research. Vol.5, No.1, pp.33-70, March 2017 
9. Kpolovie, Peter. (2016). INTELLIGENCE AND ACADEMIC ACHIEVEMENT - A LONGITUDINAL SURVEY.

10. Mohd Mohzan M., Hassan N., Halil N. (2012). The Influence of Emotional Intelligence on Academic Achievement. Procedia - Social and Behavioral Sciences 90 (2013) 303 - 312.

11. Parkins, $\boldsymbol{R}$. (2012). Gender and Emotional Expressiveness: An Analysis of Prosodic Features in Emotional Expression. Retrieved from: https://www.secretintelligenceservice.org/wpcontent/uploads/2017/02/Paper-6-Parkins-Genderand-Emotional Expressiveness_final.pdf

12. Ghabanchi, $Z$. and Rastegar $R$. (2014). The Correlation of $I Q$ and Emotional Intelligence with Reading Comprehension. The Reading Matrix (C) 2014 Volume 14, Number 2, September 2014.

13. Singh, A; Kaur, $P$ and Singh, T. (2010). Spiritual intelligence, altruism, school environment and academic achievement as predictor of mental health of adolescents [online]. Journal of Exercise Science and Physiotherapy, Vol. 6, No. 1, Jun 2010: $\quad 34-38$. Availability: <https://search.informit.com.au/docu mentSummary; $d n=842071053240778 ;$ res $=$ IELHE A>_ISSN: 0973-2020. [cited 02 Dec 20].

14. Skourdi, S., \& Rahimi, A. (2010). The relationship of emotional intelligence and linguistic intelligence in acquiring vocabulary. California Linguistic Notes, 35(1), 23-45. 